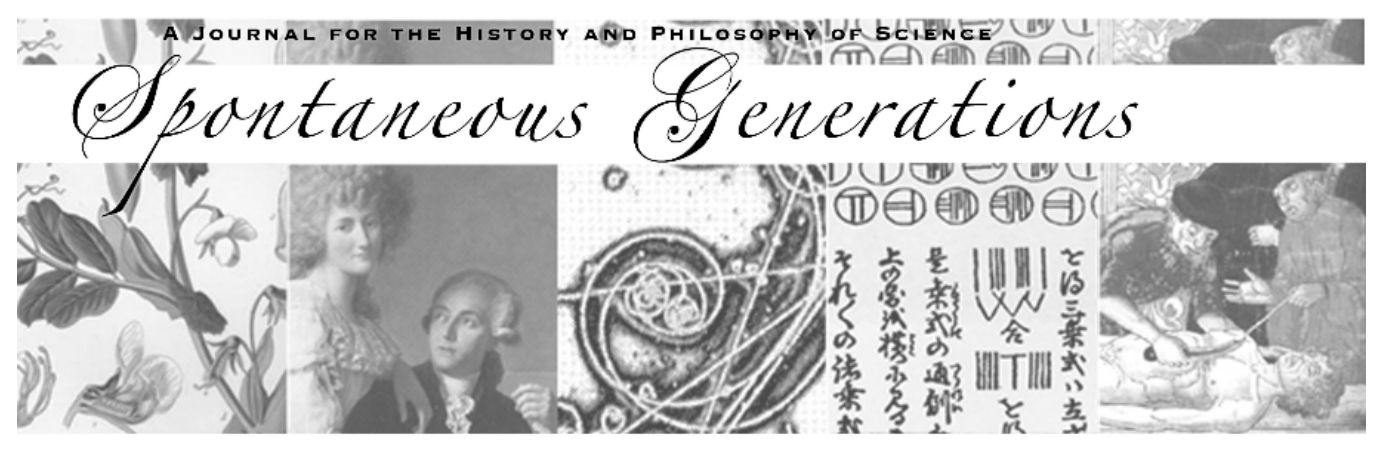

\title{
Visual Representation and Science: Editors' Introduction
}

\section{Author(s): Ari Gross and Eleanor Louson}

Source: Spontaneous Generations: A Journal for the History and Philosophy of Science, Vol. 6, No. 1 (2012) 1-7.

Published by: The University of Toronto

DOI: 10.4245 /sponge.v6i1.18644

\section{EDITORIAL OFFICES}

Institute for the History and Philosophy of Science and Technology

Room 316 Victoria College, 91 Charles Street West

Toronto, Ontario, Canada M5S 1K7

hapsat.society@utoronto.ca

Published online at jps.library.utoronto.ca/index.php/SpontaneousGenerations ISSN 19130465

Founded in 2006, Spontaneous Generations is an online academic journal published by graduate students at the Institute for the History and Philosophy of Science and Technology, University of Toronto. There is no subscription or membership fee. Spontaneous Generations provides immediate open access to its content on the principle that making research freely available to the public supports a greater global exchange of knowledge. 


\title{
FocusEd Discussion
}

\section{Visual Representation and Science \\ Editors' Introduction*}

\author{
Ari Gross ${ }^{\dagger}$ \\ Eleanor Louson
}

The theme of visual representations in science was already central to our research when we attended the $6^{\text {th }}$ European Spring School on History of Science and Popularization in Menorca, Spain, in 2011. As discussed in the review of this conference by Ignacio SuAY-MAtalLana and Mar CuencA-Lorente (245), many participants not only described the particulars of the generation of individual images, but also broader issues surrounding the constitution of visual domains. We were impressed by the range of scholarship surrounding the production, circulation, and interpretation of a wide variety of images, yet a nagging question remained: what issues unite this diversity of research and compel us to investigate such representations? Beyond their novelty, why study scientific images at all?

Introductions to the theme of visual representations in science often begin with well-worn tales about the tendency of traditional history and philosophy of science to ignore images before detailing the triumphant resurgence in contemporary interest. Indeed, the oft-asserted interest in scientific images is not mere rhetoric: since at least the early 1990s the study of the pictures that surround the practices of science and natural philosophy have repeatedly come to the fore. This is evident in the canonical HPS and STS texts dealing with the visual, with Latour and Woolgar (1979), Lynch (1988), Kaiser (2005), and Daston and Galison (2007) among the most prominent. Among historians, the past two decades have produced at least a half-dozen major edited volumes dedicated to the subject of images in science. These include, among others, Representation in Scientific Practice (1990-with a new edition currently in

* The authors would like to thank Agnes Bolinska and Isaac Record for their helpful advice.

$\dagger$ Ari Gross is a PhD candidate at the Institute for the History and Philosophy of Science and Technology at the University of Toronto. His primary research is on the history and philosophy of diagrams of "invisible" objects, although he also holds a strong interest in anatomical representations. He is also co-curator of the University of Toronto Scientific Instrument Collection (www.utsic.org).

$\ddagger$ Eleanor Louson is a PhD student in Science and Technology Studies at York University. Her current research deals with wildlife films and their representation of animal behaviour.

Spontaneous Generations 6:1 (2012) ISSN 1913-0465. University of Toronto.

Copyright 2012 by the HAPSAT Society. Some rights reserved. 
production), Non-Verbal Communication in Science Prior to 1900 (1993), Picturing Knowledge (1996), Picturing Science Producing Art (1998), The Power of Images in Early Modern Science (2003), and The Art of Natural History (2008). Among philosophers, Mitchell (1994) proposed that philosophy's focus on, and anxiety about, visual representation constituted a "pictorial turn," with foundations in Peirce's semiotics, Goodman's "languages of art," and early Wittgenstein's "picture theory" of meaning. For Mitchell, such a turn requires interdisciplinary critique, "a postlinguistic, postsemiotic rediscovery of the picture as a complex interplay between visuality, apparatus, institutions, discourse, bodies, and figurality" (16). For philosophers of science, the increased interest in models and model-based reasoning over the last decade has ensured a vibrant discourse over the status and functions of visual imagery in scientific practice. As an outgrowth of the "practical turn," an increased emphasis on scientific models has resulted in seeing images in a new light. Morrison and Morgan (1999), Suárez (2004), Frigg (2006), Contessa (2007), and Knuuttila (2011), among others, have addressed the questions of what constitutes scientific representations and how they are used to generate knowledge. While the debates surrounding scientific representations and models are far from over-as indicated by several of the papers found in this focused discussion-there is certainly a consensus that images contribute to scientific knowledge and therefore can't be overlooked.

What we wish to do here is to unpack the anxieties underlying and motivating the continued interest in scientific visual representations. Indeed, the wide array of scholarship surrounding scientific visual representations-excellent as it may be-runs the risk of obfuscating the central themes concerning the uses of images in science. Rich, textured case studies-although useful-don't, on their own, help us understand what exactly is at stake. In other words, do we risk (pace Gooding 2005) not seeing the forest for the trees?

The papers contained in this focused discussion exhibit a similar diversity of approach and scope to those presented at the 2011 Spring School in Menorca. However, we have found that the papers that follow share unexpected common ground in terms of their concerns, themes, and outlook for future progress on this subject. We believe that they will help clarify the stakes for research on visual representation and science.

The first papers in this focused discussion are concerned with specific visual practices. Sachiko KusukawA's “Thomas Kirke's copy of Philosophical Transactions" gives us a glimpse into the imaging practices of a late-seventeenth century gentleman and his hand-drawn copy of a plate from the Royal Society's Philosophical Transactions, showcasing the links between drawing and seeing. In "Visual Representation and Science: Visual Figures of the Universe between Antiquity and the Early Thirteenth Century," Barbara OвRIST describes how images functioned in Medieval cosmographical texts. Tracking the development 
of changing approaches to cosmographical diagrams from Antiquity until the High Middle Ages, Obrist asks "in what circumstances and to what end do authors refer to visual representations?" (16) The history of the modern observatory and the visual and epistemic practices of astronomy are the topic of Ian LowRIE's full-length article "On Adaptive Optics: The Historical Constitution of Architectures for Expert Perception in Astronomy." Lowrie's history is illustrative of Rheinberger's understanding of scientific systems and their supportive graphematic space (1997). Laurent DISSARD explores the ramifications of a discipline's visual style in "Seeing the Past from Nowhere: Images and Science in Archaeology," which addresses visual practices in archaeological site reports. Dissard argues that these images "bolster the report's objectivity by 'taking the dirt out of it'" (32). Anthropologist Matt Spencer's "Trouble with Images in Computational Physics," based on interviews with practicing scientists, reveals the tension surrounding the status of images among practicing scientists. While visual representations are powerful and useful tools, their capacity to be used inappropriately risks engendering disproportionate trust.

These concerns about images and trust voiced by Spencer's scientists resonate with several other papers that explore the role of scientific images in establishing trust and authority. In "The testimony of my own eyes': The Strange Case of the Mammal with a Beak," Martin Kemp discusses the role of visual representations and specimens in convincing others of the existence of "that most improbable mammal with a beak," the duck-bill platypus (45). In doing so, Kemp explores the representations' "collective visual qualities that serve to inculcate trust" (44), what he calls the "rhetoric of reality" (44). Issues of trust and authority are also found in Cindy Stelmackowich's "The Instructive Corpse: Dissection, Anatomical Specimens, and Illustration in Early Nineteenth-Century Medical Education." This piece explores the role of medical textbook illustrations in the training of future physicians and the maintenance of their professional identity.

The link between images and authority is particularly pressing in considerations of science and the public. In "A Matter of Scale: The Visual Representation of Nanotechnologies," Koen BEUMER discusses the visual representation of nanotechnology through "scaling" images, which explain the nanoscale with reference to familiar everyday objects. Beumer argues that these images are far from neutral: in addition to their explanatory role, they are frequently bound up with an association of multiple meanings. In a similar vein, Martin MAHony and Mike Hulme's "The Colour of Risk: An Exploration of the IPCC's 'Burning Embers' Diagram” examines one prominent visual representation within the climate change debate. By following the production, use, and reception of the "burning embers" diagram, Mahony and Hulme assess the role of the scientific expert in the visual communication of risk and danger. The importance of images in the relationship between scientists and their 
publics is also addressed by Jennifer TUCKER in “'The Hidden World of Science': Nature as Art in 1930s American Print Advertising." Here, Tucker presents the overlooked history of Philip O. Gravelle, whose acclaimed photomicrographs were employed in advertising campaigns for consumer products. Like Beumer and Mahony and Hulme, Tucker also demonstrates how the epistemic status of scientific images is often accompanied by issues of authority.

Annamaria CARUSI focuses our attention to more philosophical matters in her "Making the Visual Visible in the Philosophy of Science." Here, she identifies several issues, such as the untenability of certain traditional philosophical distinctions, that must be addressed in order to understand the production of knowledge in contemporary data-intensive computational practices and the role that visualization plays in these processes. In his "How Much Work do Scientific Images Do?", Stephen DownEs argues for a multi-faceted approach to understanding the roles that images play in scientific discourse. He asserts, contra Perini (2005), that images can act both as evidence and models, stressing the need for a multiple, rather than unified, view of scientific visual representations. William Goodwin's "Visual Representations of Structure and the Dynamics of Scientific Modeling" posits a different way in which images are multi-faceted. In focusing on model dynamics, in particular early twentieth-century molecular models and their impact on the development of conformational analysis, Goodwin articulates the relationship between dynamical models and their experimental consequences. Responding to critiques of her controversial earlier work (2005), especially those by Goodwin (2009), Laura PERINI seeks to reestablish a place for truth in scientific visual representations in "Truth-bearers or Truth-makers?" Here, Perini proposes that not all images (specifically those mentioned by Goodwin) are used for model-based reasoning; instead, some images are not involved in the production of new scientific knowledge but are rather "claim-making representations"-in other words, "truth-bearers." In all three of these papers, the notion that there is simply no single, unified way to think about the functions that visual representations play in the practice of science comes across clearly. In addition, these authors emphasize the need for philosophers to pay close attention to the roles of images in scientific reasoning and practice.

A selection of papers are concerned with the formal and informal aspects of visual representations, particularly those of "invisible" objects. Michael Jeremy BARANY investigates representations of the Euclidean point in Early Modern geometry textbooks in "'That small and unsensible shape': Representing the Euclidean Point in Sixteenth-Century print." In discussing the "label-dot diagrams" that introduce the Euclidean point, Barany addresses the paradoxical nature of visual representations in geometry and explores the relationship between the geometrical point and its visual stand-in, the dot. In his "On the Intrinsically Ambiguous Nature of Space-Time Diagrams," Elie During 
emphasizes the ability of Minkowski diagrams to not only act as useful heuristics but also as formal displays of different inertial frames. In particular, During identifies the advantage of Minkowski diagrams in their ability to depict multiple kinematical perspectives at once. A different class of diagram, also from the field of physics, is discussed by Adrian Wüthrich in his "Interpreting Feynman Diagrams as Visual Models." Here, Wüthrich argues the counter-point to During. Despite their capacity for formal representation, Wüthrich claims that Feynman diagrams have the ability to partially represent subatomic interactions, and should thus be understood as models whose significance need not be strictly limited to their explicit content. Although the representations discussed in these papers are highly technical, each class of image is also capable of carrying broader associations, and of mediating between both formal and informal meanings.

The advent of the digital humanities has been perceived by scholars of the sciences as posing new opportunities and challenges in the development of their research programs. Both of these perspectives are represented in this volume. Klaus HentsCheL's "Making the Invisible Hands Visible: Image-Makers in Science, Medicine and Technology" describes the Stuttgart Database of Scientific Illustrators 1450-1950 (DSI) and its aim to document and make public the rich and overlooked contributions to scientific image-making by "draughtsmen, engravers, etchers, woodcutters, painters, colourists, lithographers, photographers, and other illustrators" (183). In drawing our attention to these long-ignored artisans, Henstchel and the DSI hope to offer historians a rich new resource for scholarship. Although appearing as an Opinion piece, Maura Flannery's "Flatter than a Pancake: Why Scanning Herbarium Sheets Shouldn't Make them Disappear" also addresses the consequences of new methods of scholarship, arguing that original specimens from botanical herbaria ought not be discarded in the face of their digitization. While the advantages of digital herbaria are clear, Flannery stresses that some aspects of these specimens simply can't be captured by a virtual collection.

In a discussion devoted to issues of visual representation, it was unexpected to receive a paper extolling the potential of sound. Edward JONES-IMHOTEP's "Sound and Vision" calls our attention to sound as an untapped epistemic resource. Drawing on the examples of auscultation and microscopy, Jones-Imhotep emphasizes that what we consider to be purely visual representations are often multisensory in origin, thus expanding the scope and territory of investigations of scientific representations.

Returning to our initial concern, there are countless stories to tell about visual representation in science. Nevertheless, we can identify key undercurrents running through these diverse papers, motivated by the following questions: what roles do images and models play in scientific reasoning and practice? How do images engender trust and authority, especially among the public? 
What do we make of images' capacity to embody multiple meanings and to operate within diverse contexts? Taking these questions seriously means that scholars must get past treating images as novel subjects of historical and philosophical inquiry and should instead regard them as essential and substantive contributors to science.

We sincerely hope that this focused discussion contributes to an exciting maturation of the study of visual representation and science.

\author{
ARI Gross \\ IHPST, University of Toronto \\ 91 Charles Street West \\ Toronto, ON M5S 1K7 \\ CANADA \\ ari.gross@utoronto.ca \\ ELEANOR Louson \\ Graduate Program in Science \& Technology Studies, York University \\ 218 Bethune College \\ 4700 Keele Street \\ Toronto, ON M3J 1P3 \\ CANADA \\ elouson@yorku.ca
}

\title{
RefERENCES
}

Baigrie, Brian S., ed. 1996. Picturing Knowledge: Historical and Philosophical Problems Concerning the Use of Art in Science. Toronto: University of Toronto Press.

Contessa, Gabriele. 2007. Scientific Representation, Interpretation, and Surrogative Reasoning. Philosophy of Science 74(1): 48-69.

Daston, Lorraine, and Peter Galison. 2007. Objectivity. New York: Zone Books.

Frigg, Roman. 2006. Scientific Representation and the Semantic View of Theories. Theoria 21(1): 49-65.

Gooding, David C. 2005. Seeing the Forest for the Trees: Visualization, Cognition, and Scientific Inference. In Scientific and Technological Thinking, eds. Michael E. Gorman, Ryan D. Tweney, David C. Gooding and Alexandra P. Kincannon, 173-218. Mahwah, NJ: Lawrence Eribaum Associates.

Jones, Caroline A., and Peter Galison. 1998. Picturing Science, Producing Art. New York: Routledge.

Kaiser, David. 2005. Drawing Theories Apart: The Dispersion of Feynman Diagrams in Postwar Physics. Chicago: University of Chicago Press.

Knuuttila, Tarja. 2011. Modelling and representing: An artefactual approach to model-based representation. Studies in the History and Philosophy of Science 
42(2): 262-71.

Lefèvre, Wolfgang, Jurgen Renn, and Urs Schoepflin, eds. 2003. The Power of Images in Early Modern Science. Basel: Birkhäuser.

Latour, Bruno, and Steve Woolgar. 1979. Laboratory Life: The Social Construction of Scientific Facts. Princeton, NJ: Princeton University Press.

Lynch, Michael. 1988. The Externalized Retina: Selection and Mathematization in the Visual Documentation of Objects in the Life Sciences. Human Studies 11(2/3): 201-34.

Lynch, Michael, and Steve Woolgar, eds. 1990. Representation in Scientific Practice. Cambridge, MA: The MIT Press.

Mazzolini, R. G., ed. 1993. Non-Verbal Communication in Science Prior to 1900. Bublioteca di Nuncius: Studi e Testi XI. Florence: Leo S. Olschki.

Mitchell, William J. Thomas. 1994. Picture Theory: Essays on Verbal and Visual Representation. Chicago: University of Chicago Press.

Morrison, Margaret, and Mary S. Morgan. 1999. Models as Mediating Instruments. In Models as Mediators: Perspectives on Natural and Social Science, eds., M. S. Morgan and M. Morrison, 10-37. Cambridge: Cambridge University Press.

O'Malley, Therese, and Amy R. W. Meyers, eds. 2008. The Art of Natural History: Illustrated Treatises and Botanical Paintings, 1400-1850. New Haven, CT: Yale University Press.

Rheinberger, Hans-Jorg. 1997. Toward a History of Epistemic Things: Synthesizing Proteins in the Test Tube. Stanford, CA: Stanford University Press.

Suárez, Mauricio. 2004. An Inferential Conception of Scientific Representation. Philosophy of Science 71(5): 767-79. 